


\section{REFUGEE YOUTH AND MENTAL HEALTH: PRINCIPLES FOR}

RESETTLEMENT SUPPORT

\section{By Emily Pelley}

\section{PhD Candidate,}

Dalhousie University

\section{ABSTRACT}

The issue of young people on the move has attracted significant international attention as the amount of displacement due to armed conflict has steadily increased in recent years. The UNHCR reports that 68.5 million people have been displaced worldwide, with just over half of them being under the age of $18 .{ }^{1}$ Armed conflict often forces families to flee their homes and communities in search of safety. For those who can go to a new country there are both benefits and challenges to navigate. The experiences of youth displacement because of armed conflict is an area that needs further research.

This paper explores the current situation of youth displacement and the importance of informed mental health support throughout their transition experience in a new country. A young person's resilience through the experience of integrating into a new home is not merely a description of their personality but a combination of the personal and social resources that can positively impact their well-being. This social ecological perspective of resilience is a useful framework for responding to the needs of young refugees.

1 United Nations Refugee Agency, Figures at a Glance, 2018. 


\section{INTRODUCTION}

This paper will explore the current situation of youth displacement and the importance of informed mental health support throughout their transition experience in a new country. Mental health is defined in this paper to broadly include a young person's psychopathology (i.e. psychological and behavioural dysfunction) as well as self-esteem and overall well-being. ${ }^{2}$ Looking at the integration process for refugee young people from a mental health perspective allows for a discussion of how individual strengths and environmental factors influence each other. In this paper, the terms children and youth, and young people are used interchangeable to refer to those under the age of 25 , in keeping with the UNESCO definition of youth. ${ }^{3}$ Refugee young people arrive in their settlement countries from various backgrounds, socioeconomic status, education, arrival pathways, family structure, and English language skills. ${ }^{4}$ A young person's resilience through their integration is not merely a description of their personality but a combination of the personal and social/environmental resources that can positively impact their well-being. This social ecological perspective of resilience is a useful framework for responding to the needs of young refugees.

This paper will begin with a discussion of youth displacement and the impact of war and armed conflict on their well-being. The mental health response for those young people who settle in North America will be discussed, presenting some key principles for effectively supporting refugee young people through their transition and integration into a new home. Ensuring the support refugee young people throughout their integration into their new society will be positive for both them and their community.

\section{YOUNG REFUGEES AND MENTAL HEALTH SUPPORT}

The issue of young people on the move has recently garnered significant international attention as the amount of displacement due to armed conflict has steadily increased in recent years. The UNHCR reports that 68.5 million people have been displaced worldwide, with just over half of them being under the age of $18 .{ }^{5}$ According to the United Nations Convention on the Rights of the Child, those under the age of 18 are considered children. ${ }^{6}$ Armed conflict often forces children to leave their homes and communities in search of safety. Contemporary civil wars show a total societal crisis, where the social order is disrupted leaving civilians -

2 Beiser \& Mantini, The Mental Health of Immigrant and Refugee Youth in Canada, (Oxford University Press- Canada, 2018), 378-395.

3 UNESCO, What do we mean by youth? United Nations Educational, Scientific, and Cultural Organization. 2017.

4 Gifford \& Edmee, Defining refugee youth settlement and why it matters, (The Federation PressAustralia, 2015) 118-132.

5 United Nations Refugee Agency, Figures at a Glance, 2018.

6 UNCRC, Convention on the Rights of the Child, 1989. 
particularly women and children - vulnerable. ${ }^{7,8}$ Recent decades have seen a shift in the nature of war and armed conflict: a shift from interstate to civil conflict which has been characterized by an increase in the number of civilian fatalities. In some cases, civilians have been the targets of hostility with the purpose weakening the opposing force. The complexities of modern armed conflict involve children through traditional warfare, civil unrest, guerrilla fighting, and terrorism. ${ }^{9}$

In Jo Boyden's article about children's experiences in conflict, she argues that the mainstream models for interventions for children affected by violence do not sufficiently capture the large number of young people affected. She argues that in most conflicts, many war-affected children remain untouched by relief efforts because of a tendency of relief programs to be "spectacular" - focusing on sub-populations such as child combatants, refugees, orphans, etc., while overlooking the larger population indirectly impacted by the conflict. ${ }^{10}$ Whether they are displaced or isolated in some way from humanitarian assistance, there is still little known about their experience and their needs. ${ }^{11}$ Assessing the full impact of violent conflict on young people must be multi-levelled in order to capture the complexity of their experience.

In many situations, refugee and internally displaced persons camps have become more long-term dwellings because of a drawn-out conflict or the destruction of their homes. One example of this is the Bhutanese refugees who were violently persecuted by their government based on their Nepali ethnicity. More than 100,000 people fled in the early 1990's and spent $15-20$ years in refugee camps. Since 2008, a large number have been resettled around the world, though there are still approximately 12,000 refugees still living in camps with nowhere to go. ${ }^{12}$ Living conditions in these camps is often substandard, leaving inhabitants vulnerable to many risks such as violence and disease. ${ }^{13}$ Those refugees living in foreign cities and countries face a unique set of challenges. In a study by Mann (2012), it was determined that the Congolese refugee children living in Dar es Salaam faced intense physical challenges, with limited access

7 Catani, Schauer, Elbert, Missmahl, Bette, \& Neuner, War trauma, child labor, and family violence: life adversities and PTSD in a sample of school children in Kabul (2009) 163-171.

8 Honwana, \& De Boeck, Makers \& breakers: children and youth in postcolonial, (Oxford: Africa World Press, 2005).

9 Cook, \& Wall, Children and armed conflict: Cross-disciplinary investigations (Springer, 2011).

10 Boyden, Children's experience of conflict related emergencies: some implications for relief policy and practice, (1994) 254-267.

11 Boyden \& Mann, Children's risk, resilience, and coping in extreme situations, (Sage Publications, 2005) 26.

12 Maung, No way home: time runs out for Bhutanese refugees in Nepal, IRIN, October 7, 2016.

13 Olujic, Children in extremely difficult circumstances: war and its aftermath in Croatia (University of California Press, Los Angeles, CA, 1998) 318-330. 
to healthy food and shelter. Yet, the young people she interviewed were more distressed by the lack of social support and the discrimination they felt in their new home. The marginalization they experience can exacerbate the effects of the war on these young people's lives, as it isolates them from the support that can foster their resilience processes. ${ }^{14}$

Canada has long been a haven for refugees from around the world. Nearly $10 \%$ of Canada's annual immigration quota is made up of refugees. ${ }^{15}$ According to Citizenship and Immigration Canada, an average of 25,000 refugees were admitted annually to Canada over the last decade. ${ }^{16}$ However, in response to the crisis in Syria, the Canadian government resettled approximately 40,000 Syrian refugees between November 2015 and January 2017 in 350 communities across Canada. Most of this population had fled violence and armed conflict, in search of a safe place to live. Finding the best way to support these young refugees coming from such a situation to their new environment in North America is critically important.

\section{6 The marginalization they experience can exacerbate the
effects of the war on these young people's lives, as it isolates
them from the support that can foster their resilience
processes.}

Research has shown that childhood exposure to violence can result in negative mental health outcomes for the young person and their family including post-traumatic stress, depression, anxiety, substance abuse, risky sexual behaviour, suicidal behaviour, and difficulties maintaining healthy relationships later in life. ${ }^{17}$ Being witness to, or engaging in, the violent activities of an armed group has negative mental health consequences. There is a whole spectrum of experiences here - from those engaged as child soldiers, porters, slaves, to those whose homes were destroyed, who witnessed violence in their communities, and to those living under constant threat of violence. Social integration following such exposure has proven to be a difficult experience for many young people. This social and economic fragmentation

14 Mann, On being despised: Growing up a Congolese refugee in Dar es Salaam (Palgrave Macmillan, London, 2012) 185-199.

15 Beiser, The health of immigrants and refugees in Canada, (2005): S30-S44.

16 Citizen and Immigration Canada. Canada Facts and Figures. 2014.

17 Anda, Felitti, Bremner, Walker, Whitfield, Perry, Dube, \& Giles, The enduring effects of abuse and related adverse experiences in childhood, (2006), 174-186;

MacMillan, Wathen, Barlow, Fergusson, Leventhal, \& Taussig, Interventions to prevent child maltreatment and associated impairment, (2009), 250-266;

Margolin \& Gordis, The effects of family and community violence on children, (2000), 445-479;

Morgan, Abdul-Razzaq, Black, Manion, Wekerle, Forshner, \& Ungar, Promising Practices to Help Children and Youth who have been Exposed to Violence. (2013);

Norman, Byambaa, Rumna De, Butchart, Scott, \& Vos, The long-term health consequences of child physical abuse, emotional abuse, and neglect: a systematic review and meta-analysis, (2012). 
that armed conflict creates often impedes the positive emotional and mental development of young people, as family structures and community supports are often damaged if not destroyed. ${ }^{18}$ The prevailing conceptual framework used to understand the effects of armed conflict on young people has been PTSD (Post-traumatic stress disorder). ${ }^{19,20}$ PTSD as defined by the American Psychiatric Association includes five criteria that specify the type of trauma experienced and the response of the individual to that trauma. ${ }^{21}$ PTSD has been identified in children affected by armed conflict (CAAC) - whether they actively engaged in the conflict or were civilians left to live through the impacts of war. In a study on the comorbidity of PTSD and depression among refugee children during armed conflict, children living in war zones were found to be at higher risk of PTSD. ${ }^{22}$ However, 'exposure to trauma' was not found to necessarily lead to PTSD, which calls into question what other factors influence a young person's reaction to armed conflict.

A systematic review by Dimitry (2011) of mental health studies done with children and adolescents living in areas of armed conflict in the Middle East categorized the factors that impact mental health to risk factors and protective factors. For example, increased exposure to violence was directly correlated with instances of PTSD; however, the presence of a supportive family would decrease PTSD. In a study by Ungar and Liebenberg, these findings were confirmed in that the presence of certain protective factors can significantly reduce the negative effects of stress with young people in difficult situations. ${ }^{23}$ An ecological perspective of this resilience - which takes into consideration the qualities of both the individual and their environment - can provide further understanding of how to promote their positive development by providing the appropriate resources. ${ }^{24,25}$

While resilience has many varied meanings, the social ecological framework leads to the following definition:

18 Freud \& Burlingham, The writings of Anna Freud: III. Infants without families: Reports on the Hamstead Nurseries, 1939-1945. (International Universities Press, 1973).

19 Friedman \& Keane, PTSD: Twenty-five years of progress and challenges, (The Guilford Press, New York, 2007), 3-18.

20 Macksoud, \& Aber, The war experiences and psychosocial development of children in Lebanon, (1996), 70-88.

21 DSM-5. Post Traumatic Stress Disorder. American Psychiatric Association, (2013).

22 Thabet, Abed, \& Vostanis, Comorbidity of PTSD and depression among refugee children during war conflict, (2004), 533-542.

23 Ungar \& Liebenberg, Cross-cultural consultation leading to the development of a valid measure of youth resilience: The International Resilience Project, (2009), 259.

24 Boyden \& Mann, "Children's risk, resilience, and coping in extreme situations", 26.

25 Ungar \& Liebenberg, Assessing resilience across cultures using mixed methods: Construction of the child and youth resilience measure, (2011), 126-149. 
In the context of exposure to significant adversity, resilience is both the capacity of individuals to navigate their way to the psychological, social, cultural, and physical resources that sustain their well-being, and their capacity individually and collectively to negotiate for these resources to be provided and experienced in culturally meaningful ways (Ungar, 2008, p. 225).

This understanding of resilience goes beyond the individual, paying attention to the interactions between the individual and their environment. In a systematic review by Tol, Song, and Jordans ${ }^{26}$, they captured both qualitative and quantitative studies that focused on resilience and mental health in children and adolescents affected by armed conflict in low and middle-income countries. Their findings support this conceptualization of resilience as a "dynamic process" 27 , suggesting that focusing on individual factors can distract researchers from the complexity of the interactions between risk and protective factors, and the individual. Therefore, an effective line of inquiry is, "what conditions allow for and sustain resilience in individuals at different moments in life?". 28 The Challenge and Resilience Model (see Figure 1, Page 75) shows the dynamic process of how risk factors and protective factors impact the integration experience and mental health of refugee young people. ${ }^{29}$ Resources, whether personal or social, can act as a buffer in a young person's life against adversity. This model demonstrates the interacting pathways that impact mental health. The ability of a young person to integrate successfully relies on the link between place and well-being - or placemaking. "Placemaking" is a young person's ability to transform the place they find themselves into their home. ${ }^{30,31}$ This includes not just physical placemaking but also the way young people can connect with their new community. The ability to make a place a home is vital to coping with stress and integration. ${ }^{32}$

Resilience is both context-dependent as well as temporally specific. The changing nature of both the individual and their environment requires attention on the successful adaptation to

26 Tol, Song, \& Jordans, Annual research review: Resilience and mental health in children and adolescents living in areas of armed conflict-a systematic review of findings in low-and middle-income countries, (2013), 445-460.

27 Ibid. p445.

28 Ferrari \& Fernando, Resilience in children of war, (Springer, New York, NY, 2013), 287-301.

29 Beiser \& Mantini, "The Mental Health of Immigrant and Refugee Youth in Canada”, 378.

30 Akesson, Refugee Youth Affected by War and Displacement: A Socio-ecological Approach, (Oxford University Press- Canada, 2018), 361-377.

31 Denov \& Akesson, Neither here nor there? Place and placemaking in the lives of separated children, (2013), 56-70. 


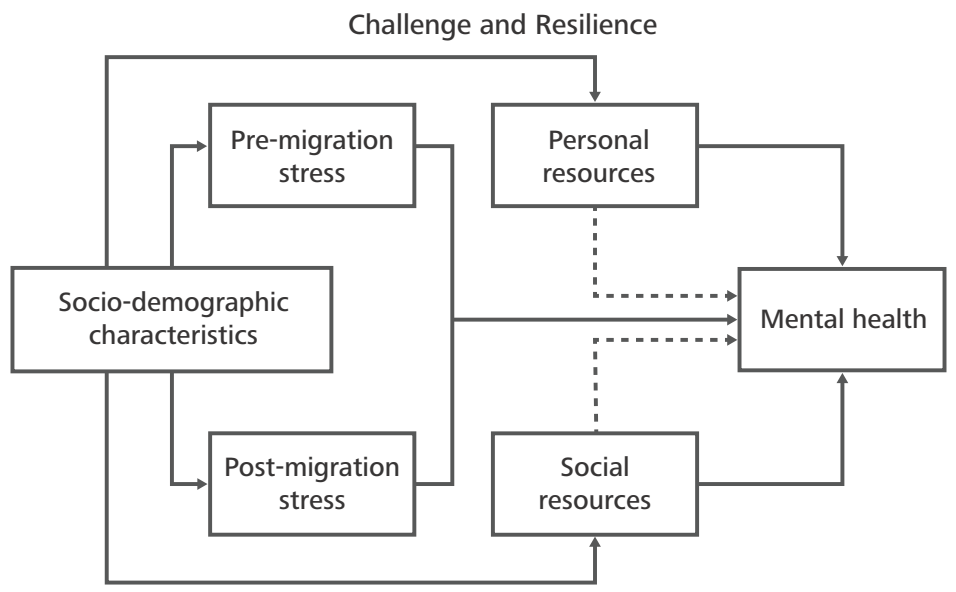

Figure 1: Challenge and Resilience: A Model of Mental Health for Refugee and Immigrant Youth ${ }^{33}$

change and how such adaptation can be facilitated in a positive way. ${ }^{33,34}$ Magid and Boothby ${ }^{35}$ align more with this perspective by approaching resilience as an ongoing process of balancing factors. They present an overview of the risks young people face in war. Drawing on their past research with children in conflict, they were able to demonstrate that if protective factors were able to out-weigh risk factors, the potential to counteract the negative impact on the young people's resilience was increased. Thus, in supporting the resilience of young people in the contexts of war and armed conflict, it is important to identify and strengthen protective factors. ${ }^{36,37}$

In Brofenbrenner's Ecological Systems Theory ${ }^{38}$ (Figure 2, Page 76), he presents the different levels that impact a child's development. When applied to the experience of refugee young people, it allows for a dynamic understanding of what factors contribute to their well-being. ${ }^{39}$ At the micro-level, for example, the importance of family in affecting young people is

33 Rutter, Resilience: Causal pathways and social ecology, (Springer, New York, NY, 2012), 33-42.

34 Ungar, Brown, Liebenberg, \& Othman, Unique pathways to resilience across cultures, (2007), 287.

35 Magid, \& Boothby, Promoting resilience in children of war, (Springer, New York, NY, 2013) 39-49.

36 Magid,\& Boothby, Promoting resilience in children of war, 39-49.

37 Kostelny \& Wessells, Child friendly spaces: Promoting children's resiliency amidst war, (Springer, New York, NY, 2013) 119-129.

38 Bronfenbrenner, The ecology of human development, (Harvard University Press, 2009).

39 Akesson, Refugee Youth Affected by War and Displacement: A Socio-ecological Approach, 361. 


\section{Chronosystem}

Changes Over Time

\section{Macrosystem}

Social and Cultural Values

\section{Exosystem}

Indirect Environment

Mesosystem

Connections

\section{Microsystem}

Immediate Environment

\section{CHILD}

Figure 2: Brofenbrenner's Ecological Systems ${ }^{42}$

significant. There are several studies that identify family as central to the well-being of their children. ${ }^{40}$ School-level support (which would be part of the mesosystem) is another effective point of engagement with young people. A Canadian example of how school-based intervention can work can be found in the Hamilton-Wentworth District School Board (HWDSB). They have provided dynamic English-language support programs specifically for newcomer young people in the area. The young people are provided with direct instruction and language training throughout the school day, with opportunities to join the wider student

40 Betancourt, Stichick, Speelman, Onyango, \& Bolton, A qualitative study of mental health problems among children displaced by war in northern Uganda, (2009), 238-256;

Garbarino, \& Kostelny, The effects of political violence on Palestinian children's behavior problems: A risk accumulation model, (1996), 33-45;

Tol, Haroz, Hock, Kane, \& Jordans, Ecological perspectives on trauma and resilience in children affected by armed conflict, (Routledge, East Sussex, UK, 2014), 193-209;

Pynoos, Steinberg, \& Wraith, A developmental model of childhood traumatic stress, (Oxford, England, John Wiley \& Sons, 1995), 72-95. 
population for certain classes like art and physical education. This has proven to support their integration into their new home by meeting their need for language and cultural instruction while also supporting social connections with Canadian students. ${ }^{41,42}$

At the exo-level of this social ecological model, the influence of organizations and government is identified. While this may not be in the direct experience of young people, the political and social climate which they create can either support or hinder innovation in how young refugees are supported through their transition. What this model offers are levels in which the varied experiences of this population can be better understood. It is important to recognize that the contexts that refugees come from vary, resulting in differing needs and values within this population group. ${ }^{43}$ Therefore, engaging refugee young people is vital for the success of a program or intervention. Creating space for youth engagement means that there are opportunities for young people to be involved in a program that is intended for them, not just as recipients of support, but as co-creators. This engagement focuses on the positive contribution that young people can make to programs and their effectiveness. Young people are then able to see that their contribution can make a difference, and that they can contribute to some positive changes in their community. In any instance of youth programming, it is important to consider the capacity of the young people in the community and what they would be both willing and able to contribute. Especially thinking of refugee youth, it is important to find ways to engage them that will help and not add stress to their lives. Youth-adult partnerships can have a positive impact on both the individuals and the success of a program or intervention. ${ }^{44}$

\section{Creating space for youth engagement means that there are opportunities for young people to be involved in a program that is intended for them, not just as recipients of support, but as co-creators.}

Using both an individual-centric and a community-wide approach to mental health and well-being support for young people is also extremely beneficial. An example of this strategy is Project SHIFA (Supporting the Health of Immigrant Families and Adolescents; SHIFA means health in Somali), a multi-tiered prevention and intervention program for

\footnotetext{
41 English as a Second Language, Hamilton-Wentworth District School Board.

42 Pent, Professional Perspective 3: High School Principal, (Oxford University Press- Canada, 2018), 172-183.

43 Zinck, Ungar, Whitman, Exenberger, LeVert-Chaisson, Liebenberg, Ung \& Forshner, Working with Children and Youth in Challenging Contexts to Promote Youth Engagement, 2013.

44 Zinck, E., et al, Working with Children and Youth in Challenging Contexts to Promote Youth Engagement, 2013.
} 
Somali youths developed by the Children's Hospital in Boston. ${ }^{45}$ Project SHIFA's model includes a population-wide resilience-building approach, a more targeted stress- reduction program for those particularly at risk, and an intensive intervention for those in crisis. ${ }^{46}$ This multi-tiered approach not only responds to the needs of those in distress, but to the important environmental elements in the community that can directly impact a young person dealing with trauma. Some of these elements can help or hinder the health process. By engaging with community members, whether in schools, community leaders, or family members, young people can be referred for care. This helps build a network of trust which can go a long way in destigmatizing mental health treatment by connecting acute care with more broad support offered to the general population. ${ }^{47,48}$

\section{CONCLUSIONS}

In this paper, some key principles have been presented as vital for effectively supporting refugee young people through their transition and integration into life in North America. Programs that include young people throughout its development, implementation, and evaluation have boasted a positive result for both the young people involved and the effectiveness of the intervention. Though this poses a challenge for working with refugee young people, it is important to realize that their perspective can offer strength and insight into what support is particularly needed. The challenge for service providers is to discover the appropriate avenue for such engagement.

A multi-tiered response can provide more broad resources for all members of the community in which young refugees are settled, from those who need acute care to those who could benefit from community-wide programs. This exemplifies Brofenbrenner's social ecological theory, allowing for support to be made available in all areas of a young person's life. It is important to ensure resources are accessible to these young people to best support their resilience. Responses to refugee young people has often focused on the psychosocial problems that arise, but it is important for programs to address not only specific mental health needs but also to their wider social context. ${ }^{49}$ Research is needed to explore how psychosocial problems

45 Children Hospital Boston, Project SHIFA: Supporting the Health of Immigrant Families and Adolescents School-based Trauma Systems Therapy for Somali Adolescent Refugees Children's Hospital Boston, Massachusetts, 2018.

Ellis, Miller, Abdi, Barrett, Blood,\& Betancourt, Multi-tier mental health program for refugee youth, (2013), 129.

47 Ibid, 129.

48 National Research Council \& Institute of Medicine, Preventing Mental, Emotional, and Behavioral Disorders Among Young People: Progress and Possibilities, 2009. 
are both perceived and handled by different local communities and cultures. ${ }^{50}$ These dynamic processes can be better understood using this broad, ecological perspective, both in research and practice. Ensuring we support refugee young people throughout their integration into their new home will be positive for not just them but for the community and nation. Our young people are our future and safeguarding their positive development must be our priority.

Emily Pelley (née Zinck) is a PhD candidate in the Interdisciplinary program at Dalhousie University, doing research on services for refugee children and youth affected by armed conflict. In 2010, Emily received her MSc with distinction in International Health from Queen Margaret University in Edinburgh, Scotland. Prior to this, she received her BA (Honours) from Dalhousie University in International Development Studies. Emily has worked on various research projects with vulnerable young people, including work with the Roméo Dallaire Child Soldiers Initiative. She is passionate about the fight against human trafficking and she has used any avenue that comes her way to raise awareness and mobilize people to stand up to this injustice. Her research interests include children and youth mental health, social justice, human trafficking, international humanitarian law, knowledge mobilization, and youth engagement.

50 Betancourt et al, A qualitative study of mental health problems among children displaced by war in northern Uganda, 238. 